\title{
El Facundo de Sarmiento: problematizar la obra desde sus ediciones póstumas
}

\author{
Sarmiento's Facundo: \\ Problematizing the Work \\ through its Posthumous Editions
}

\author{
Hernán Fernández \\ (D) https://orcid.org/0000-0001-7381-1443 \\ Universidad Nacional de San Juan-ConicET \\ hernan.fernan86@gmail.com
}

Resumen: En este artículo me propongo estudiar, desde la historia intelectual y la historia del libro, la trayectoria como publicación del Facundo de Domingo F. Sarmiento. Particularmente apunto a sumar conocimientos sobre un aspecto específico: examinando cómo luego del deceso del sanjuanino dicha obra fue apropiada por diferentes operaciones editoriales que buscaron adaptarla a los nuevos requerimientos intelectuales. Mi trabajo avanza sobre elementos explorados con escaso detenimiento hasta el momento, tales como los cambios aplicados al Facundo en tiempos póstumos al autor y los modos en que estas variaciones afectaron su recepción.

Palabras clave: Facundo; Sarmiento; ediciones; editores; recepción.

cómo citar: Fernández, H. (2021). El Facundo de Sarmiento: problematizar la obra desde sus ediciones póstumas. Secuencia (109), e1753. Dor: https://doi.org/10.18234/secuencia.v0i109.1753

cC Esta obra está protegida bajo una Licencia Creative Commons Atribución-NoComercial 4.0 Internacional. 
Abstract: In this article I propose to study, from the intellectual history and the history of the book, the trajectory of Domingo F. Sarmiento's Facundo as a publication. I attempt to contribute knowledge on a specific aspect, by examining the way, after the death of San Juan, this work was appropriated by various editorial operations that attempted to adapt it to new intellectual requirements. My article advances elements scarcely explored to date, such as the changes made to Facundo after the author's death and the way these variations affected its reception.

Keywords: Facundo; Sarmiento; editions; editors; reception.

Recibido: 3 de junio de 2019 Aceptado: 18 de diciembre de 2019

Publicado: 8 de marzo de 2021

\section{INTRODUCCIÓN}

T a complejidad del Facundo de Sarmiento, obra sustancial para el estudio Ldel pensamiento político decimonónico argentino y americano, ameritó la atención de disímiles áreas del conocimiento, tales como la literatura, la sociología, la filosofía, la geografía, etc. En esta ocasión me propongo abordarlo desde una clave de lectura particular: su historia como publicación, centrándome en la trayectoria póstuma que le cupo a este título sarmientino. ${ }^{1}$ No obstante, para poder avanzar sobre mi objetivo específico, es menester dar un breve rodeo por las diferentes ediciones que el mismo autor efectuó. La conjetura que acompaña esta aproximación inicial a mi tema principal entiende que Facundo durante la vida del sanjuanino resultó un texto indefinido.

La originaria edición apareció en el periódico chileno El Progreso, dentro del espacio destinado al folletín. Sarmiento empleó dos títulos: Facundo para la primera parte y Vida de Juan Facundo Qiroga para la segunda. ${ }^{2}$ Este

${ }^{1}$ Cabe recordar que el deceso de Sarmiento se produjo el 11 de septiembre de 1888.

${ }^{2}$ Según Pagliai (2012, p. 35), el título fue Civilización i barbarie. Vida de Juan Facundo Quiroga y luego resultó acotado a Facundo. Incluso Cabo y Nijensohn comparten la idea en torno al primer nombre (Cabo y Nijensohn, 2012, p. 727). Pero no advierto ni en el folletín ni en el anuncio de la publicación esa denominación, la serie inicia con el título Facundo y luego varía a Vida de Juan Facundo Quiroga. 
folletín abarcó desde la introducción - "Sombra terrible de Facundo..."- hasta el capítulo XIII "Barranca Yaco!!" El tiraje comenzó el 2 de mayo y culminó el 21 de junio. La estructura inicial del Facundo denunciaba al "caudillismo" como el principal problema de la insipiente Argentina. El final de la obra, con el asesinato de Quiroga, dejaba el camino abierto para la consolidación de Rosas en el poder. ${ }^{3}$

Al poco tiempo fue llevado al formato librario ${ }^{4}$ con el nombre Civilizacion i Barbarie. Vida de Juan Facundo Qiroga. I aspecto físico, costumbres, i abitos de la Republica Arjentina (Sarmiento, 1845). Además, inéditas partes redefinieron el contenido, Sarmiento añadió una "Advertencia del autor", párrafos preliminares donde comentaba su huida de San Juan en 1840 y dos capítulos más al final: "Gobierno unitario" y "Presente y porvenir". Principalmente en estos últimos capítulos el sanjuanino desplegaba un plan de gobierno para la futura república (Fernández, 2016) y, al mismo tiempo, intervenía políticamente buscando alentar la lucha contra Rosas mediante la exaltación de los conflictos que atravesaba la Confederación. ${ }^{5}$

En 1851 aparece otra versión bajo la denominación Vida de Facundo Quiroga $i$ aspecto fisico, costumbres $i$ hábitos de la República Arjentina, seguida de apuntes biográficos sobre el Jeneral Frai Felix Aldao (Sarmiento, 1851). En los prolegómenos del levantamiento de Urquiza, volvía el Facundo para incentivar el pronunciamiento del entrerriano contra Rosas. ${ }^{6} \mathrm{El}$ cuerpo de la obra presentó alteraciones mediante la quita de la advertencia, la introducción y los capítulos agregados previamente. Incluso optó el autor por realizar algunas correcciones, referidas a datos históricos o cuestiones gramaticales, con base

${ }^{3}$ Posteriormente, entre octubre de 1845 y febrero de 1846, en el periódico El Nacional -de Montevideo- tuvo lugar una reproducción del folletín de El Progreso. Al ser una versión del Facundo que se limita a transcribir la primera realizada por Sarmiento, opté por no considerarla entre las principales a tener en cuenta dentro de la trayectoria de la obra; sin embargo, es necesario tener presente su existencia.

${ }^{4}$ Palcos (1934, p. 19) señala que el libro habría aparecido el 28 de julio.

${ }^{5}$ En estas páginas Sarmiento aludía al levantamiento correntino -desarrollado entre 1843 y 1847-, las problemáticas mantenidas con Paraguay y Brasil y la gestación del bloqueo naval anglo-francés al puerto de Buenos Aires -iniciado a mediados de 1845.

${ }^{6}$ Urquiza hizo pública su decisión de enfrentar al gobernador de Buenos Aires el 1 de mayo de 1851. Sarmiento previamente había advertido la tensión entre ambos líderes federales, por ello publicó Argirópolis en 1850 y en abril de 1851 ya tenía lista la segunda edición libraria del Facundo (Fernández, 2017). 
en indicaciones de Valentín Alsina. ${ }^{7}$ Agradeciéndole al político unitario por sus observaciones, Sarmiento colocó una carta prólogo dirigida a este.

Al culminar la vida de Quiroga el editor agregó documentos - proclamas emitidas por el riojano- para fundamentar lo planteado en el texto. Al mismo tiempo, se anexó la reseña efectuada por Charles Mazade para la revista francesa Ambos Mundos, mostrando de esa manera la aceptación que el relato había logrado en Europa. La principal novedad, atendiendo la intención política del sanjuanino, emerge en la decisión de incorporar: Aldao, texto que pasaría a integrar el Facundo definitivamente. ${ }^{8}$ En dicha semblanza el autor presentaba otro modelo de "caudillo", en este caso surgido durante las guerras de independencia. Con Aldao y la eliminación de los capítulos finales, el mensaje del Facundo adquiría innovación al centrarse principalmente en el drama de los "caudillos".

En la tercera edición libraria, fechada en 1868, los amplios títulos fijados en los libros previos resultaron acotados a Facundo; ó, civilizacion i barbarie en las pampas arjentinas (Sarmiento, 1868). Las partes en general se mantuvieron pero la vida del "chacho" Peñaloza -El chacho, ultimo caudillo de la montonera de los llanos. Episodio de 1863-vendría a engrosar la nueva configuración. En plena campaña presidencial, Sarmiento desarrollaba en dicha biografía otro tipo de "caudillo", en este caso actuando en la etapa constitucional suscitada desde 1853. Principalmente el autor exhibía un relato donde él mismo figuraba como el dirigente que supo vencer al "caudillismo" cuando ejerció la gobernación de San Juan (1862-1864) durante el último levantamiento del "chacho". 'Sintetizando, luego de varios años el Facundo reaparecía con inédita estructura, recargada contra el "caudillismo" debido a la unión de Quiroga,${ }^{10}$ Aldao y el Chacho.

7 También en la grafía se aplicaron modificaciones, empleando por ejemplo el uso de la "u" junto a la "q".

${ }^{8}$ El título original de Aldao es Apuntes biográficos, precedió a la historia de Facundo Quiroga y tuvo una trayectoria editorial similar a esta última: primero se imprimió en las páginas de El Progreso -en febrero de 1845- y al poco tiempo salió en folleto.

9 En 1863 El "chacho" Peñaloza llevó adelante un levantamiento montonero, finalmente sería vencido y ajusticiado sin juicio previo ese mismo año. La biografía que escribe Sarmiento apunta, entre otros tópicos, a exaltar la manera en que se llevó adelante la lucha contra el "caudillo" y su montonera.

${ }^{10}$ Una aclaración necesaria sobre el uso que emplearé del título Quiroga. Ya que, siguiendo con una de las hipótesis a desarrollar, el Facundo desde 1851 pasaría a estar integrado por más semblanzas de "caudillos", considero congruente diferenciar dentro de la obra los distintos textos biográficos. En consecuencia, en ciertas oportunidades adopto el nombre empleado en las Obras de Sarmiento (1889a) -Quiroga-para referirme a la vida del líder riojano muerto en 1835 
Para 1874 el escrito fue nuevamente modificado. Las partes quitadas en 1851, salvo la advertencia, volvieron al cuerpo de la obra. ${ }^{11}$ El sanjuanino culminaba la presidencia iniciada en 1868 y optaba por despedirse con el relato que le había servido, entre otras cuestiones, para denunciar los males argentinos y mostrar el plan de superación para el "caudillismo". Siguiendo ese fin, se colocó un frontispicio donde Sarmiento lucía la banda presidencial. El Facundo definitivo constaría de las semblanzas sobre Quiroga -con quince capítulos, según la edición libraria de 1845-, el "fraile" Aldao y el "chacho" Peñaloza.

Partiendo de estos aspectos característicos del Facundo durante la vida de Sarmiento, destacan al menos dos consideraciones. Primero, el autor entiende a su publicación como elemento político y, en consecuencia, según las necesidades coyunturales lo reescribe para concretar diversas finalidades. Entonces, y como segundo punto, Facundo no tuvo contenido único durante la vida del sanjuanino. Al contrario, es destacable señalar que la mutabilidad de las partes conformó uno de los rasgos principales del escrito. En otras palabras, la intelección del texto variará según la edición estudiada. No obstante, luego de tal peregrinar, la obra adquiere estructura definitiva en 1874, donde Sarmiento integra las piezas esenciales a su juicio: Quiroga (quince capítulos), Aldao y el Chacho.

Llegado este punto del artículo es preciso advertir que, producido el deceso del autor, el Facundo seguirá editándose mediante diversas publicaciones que lo adaptarán al nuevo público lector. Mi propuesta de trabajo, como lo he indicado, avanzará sobre este aspecto y buscará exhibir cómo el Facundo fue cambiado, alterando de este modo la comprensión de la obra. Para ello me valdré, tal como puede apreciarse en las páginas anteriores, de los presupuestos teóricos-metodológicos de la historia intelectual y su consideración de los textos desde la dimensión performativa: entendiéndolos como elementos de intervención en las diferentes coyunturas para las que se piensan (Palti, 2009). Además daré nuevas entradas al objeto a partir de las herramientas que brinda la historia del libro y las ediciones. ${ }^{12}$

y, de ese modo, distinguirla del resto de las semblanzas que componen el Facundo. El mismo criterio aplico al utilizar los nombres Aldao y el Chacho.

${ }^{11}$ Sobre el nombre del libro aplicó el autor breves modificaciones en el uso de signos de puntuación y en la grafía para redefinirlo en Facundo ó civilizacion i barbarie en las pampas argentinas.

${ }^{12}$ En este punto sigo los postulados de Chartier (1993) cuando discrimina al texto del libro, sosteniendo que este último es el soporte pero "cuyos dispositivos y organizaciones guían 
Retomando las propiedades del Facundo y su historia, vale enfatizar en la existencia de un complejo grupo de investigadores interesado en mostrar las diferencias entre las ediciones. Para continuar con mi exposición, indagaré principalmente los aportes de Alberto Palcos, referente indiscutible en los estudios atinentes a la trayectoria editorial de la obra. Ahora, mi lectura de la producción de Palcos, y de la tradición que lo continuó, pretende develar que no sólo historiaron al Facundo, sino que además fijaron la necesidad de definir un contenido canónico para la nueva generación de lectores. Avancemos sobre este último aspecto.

\title{
EL FACUNDO Y SU HISTORIA SEGÚN PALCOS
}

\begin{abstract}
Alberto Palcos (1929) inició el análisis sistemático del Facundo y sus ediciones. Primeramente refirió al tema en Sarmiento, producción de tinte biográfica, donde puso a consideración distintos datos sugestivos para pensar en la transformación que sufrió el Facundo durante la vida del sanjuanino. ${ }^{13}$ Entre otras cuestiones, Palcos advierte que la obra, en el transcurso de las tiradas librarias, se articuló con Aldao y el Chacho. Respecto a Aldao, lo destaca como antecedente directo del Facundo y añade que "más tarde sería incluido en $\mathrm{Ci}$ vilización y barbarie" (Palcos, 1929, p. 66). Sobre el Chacho, entiende que "con los escritos sobre Aldao y Quiroga forman su mejor libro: Civilización y barbarie" (Palcos, 1929, p. 205). En Sarmiento es reveladora la manera en que Palcos
\end{abstract}

y constriñen la operación de producción del sentido" (pp. 19-20). Según entiendo, cada edición, sean las sarmientinas o las póstumas, fueron pensadas en sus respectivos contenidos estratégicamente con el fin de realizar una determinada operación en el campo de lectura propio del momento de la publicación. Por este motivo es preciso atender los elementos editoriales -formato, títulos, imágenes, redacción, etc.- empleados para captar la atención del público lector y definir un mensaje determinado.

${ }^{13}$ Alberto Palcos fue catedrático de la Universidad Nacional de La Plata, institución en la cual dirigió la biblioteca entre 1930 y 1946. Sus primeras publicaciones tomaron temas propios de la sicología, dentro de estas se pueden citar dos libros: El genio: ensayo sobre su génesis, sus factores biológicos y sociales y sus funciones en la especie y en la sociedad (1920) y La vida emotiva (1925). Posteriormente encarrilaría los estudios hacia cuestiones históricas, publicando numerosos trabajos, de los cuales destacan: Sarmiento. La vida. La obra. Las ideas. El genio (1929), El Facundo: rasgos de Sarmiento (1934), La visión de Rivadavia (1936), Echeverría y la democracia argentina (1941), Hechos y glorias del general San Martín (1950). Palcos tiene un marcado interés intelectual en esta serie de estudios: enfatizar en la función moral de la historia para la formación de una conciencia nacional. 
(1929) interpretó que nuevas historias de "caudillos" pasaron a integrar Facundo y lo reconfiguraron en sus diversas presentaciones.

En El Facundo. Rasgos de Sarmiento (1934), posicionándose como historiador de la literatura, ${ }^{14}$ Palcos desarrolló el primer trabajo especializado en las ediciones. El investigador enseñó que en el siglo XIX existieron varios Facundo y que los cambios respondían a intereses políticos. Ahora bien, la lectura de Palcos también avanzó sobre la faceta literaria de la obra ya que, según interpretó, el texto fue escasamente apreciado en este aspecto. Conforme a la argumentación del estudioso, contemporáneos del sanjuanino como Carlos Tejedor y Juan María Gutiérrez asimilaron al Facundo entre los elementos de lucha contra Rosas pero "no se dieron cuenta al comienzo de que este libro, fruto de una casi sobre humana exaltación mental, descubría un panorama nuevo en el mundo de las letras americanas" (Palcos, 1934, pp. 19-20). Incluso el mismo Alsina en sus anotaciones "cometió el error de criticar con espíritu de cronista un recio monumento literario" (p. 69).

Llamativamente, observa Palcos, esa falta de valoración literaria continuó en el siglo xx, marco temporal donde se impone como modelo de Facundo la versión de Obras de Sarmiento (1889). ${ }^{15}$ No obstante, divisó un problema clave en esta última publicación: "reproduce, un poco arbitrariamente modificada y empeorada, la cuarta, tirada en París en 1874" (Palcos, 1934, p. 37). Esto significaba que la recepción póstuma era obturada por esa edición de Obras incapaz de contemplar los cambios aplicados por Sarmiento a la vida de Quiroga. Partiendo de tales preceptos, el erudito en cuestión establece la necesidad de volver sobre Facundo y su historia con el objetivo de recuperar su complejidad literaria. ${ }^{16}$ Para decirlo de una vez: Palcos no se limitó a historiar el Facundo, sino que intervino con la intención de consolidar una lectura literaria de la obra.

Bajo ese fin Palcos proyectó preparar la anhelada edición capaz de contener y reflejar la riqueza literaria que el texto fue adquiriendo en el trans-

${ }^{14}$ Según ya indiqué, Palcos particularizó en la necesidad de pensar la argentinidad. Con este fin, en la década de 1930, enfatizó en la invención de una tradición literaria argentina mediante las ediciones del Facundo (1938) y el Dogma Socialista (1940).

${ }^{15}$ Edición a cargo de Luis Montt, veremos las respectivas características en el apartado siguiente.

${ }^{16}$ Sobre el ejemplar de las Obras (Sarmiento, 1889a), concluía Palcos que era lamentable "como esa edición, tenida por LA DEFINITIVA, sirvió de base a TODAs las que se han sucedido hasta la fecha, TODAS REPRODUCEN AQUEL ERROR Y DIFUNDEN UN TEXTO DEFICIENTE DE 'FACUNDo'" (Palcos, 1934, p. 85). 
curso de las publicaciones. ${ }^{17}$ Consecuentemente, en detrimento de la diversidad de versiones que existieron por voluntad de Sarmiento, el trabajo del estudioso de la Universidad de La Plata apuntaba a superarlas mediante la imposición de un Facundo. ¿Cuáles eran los aspectos que según Palcos debía tener en cuenta la obra definitiva? La idea base sobre la que partía el investigador precisaba que la estructura del Facundo abarcaba quince capítulos, según el primer libro. Es decir, las restantes semblanzas que mencionó, Aldao y el Chacho, no forman parte del Facundo. En las páginas que siguen veremos que finalmente Palcos logró su objetivo al publicar la edición crítica de 1938.

Es notable el contraste entre Sarmiento (Palcos, 1929) y El Facundo (Palcos, 1934). Cuando Palcos (1929) recrea la vida del sanjuanino, entiende que el Facundo se compone por Quiroga, Aldao y el Chacho. Pero al momento de analizar las versiones específicamente (Palcos, 1934), el erudito construye una obra conformada sólo por Quiroga. Sintetizando, desde el plano histórico, considera al Facundo articulado en tres biografías; pero desde lo literario, el estudioso reduce el relato a la semblanza del "tigre de los llanos". ¿Qué permiten ver estas particularidades? Es necesario destacar que, respondiendo a determinada etapa de su trayectoria intelectual, Palcos interviene en la historia de las ediciones proyectando crear una literatura nacional. ${ }^{18}$ Por tal motivo, el Facundo que ideó apuntó a consagrarlo como la piedra basal de las letras argentinas. ${ }^{19}$

${ }_{17}$ Según Lucila Pagliai una de las definiciones en torno a qué es lo literario lo entiende como "un hecho estético -lugar de encuentro entre autores y lectores- en tanto experiencia sensible que apunta a emocionar y conmover - y también a trasmitir y a convencer- apelando a un conjunto de relaciones complejas mediatizadas por la palabra" (Pagliai, 2013, p. 14). Partiendo de esta concepción, en el transcurso del artículo al momento de referirme a "riqueza literaria", "aspectos literarios", etc.; aludiré a la forma estratégica en que se construye y busca mejorarse la redacción de un escrito ya sea mediante la utilización de determinadas palabras o conceptos, la coherencia de las oraciones, debida ubicación de signos de puntuación, etcétera.

${ }^{18}$ Entiendo por literatura nacional a aquella que "se configura como tal cuando, a lo largo del tiempo, un conjunto de obras -integrante de un determinado entorno geográfico, lingüístico y social- se organiza en un todo coherente cuyos rasgos distintivos definen/expresan/ representan, a través de la lengua compartida, las peculiaridades de la cultura y algo tan vago e intangible como la 'identidad' o el 'espíritu' de una nación" (Pagliai, 2013, pp. 13-14). Siguiendo su objetivo, afirma Palcos (1934): "Desde la publicación del Facundo, Sarmiento adentra, en la multitud de trabajos, en el corazón de la historia y del paisaje nacional, abriendo rumbos a la literatura argentina" (p. 20).

${ }^{19}$ Incluso en la segunda edición de El Facundo, Palcos (1945) suma un capítulo titulado "De la originalidad del 'Facundo"'. En las nuevas páginas compara la calidad literaria de Sarmiento con la Echeverría y Mármol; esta elección no es casual, al contrario, trae a colación a 
Vale decir, Palcos deja de ser un mero estudioso del Facundo ya que participa proponiendo su propia lectura y contenido. Luego de sus investigaciones surgirá una imprescindible bibliografía interesada en las variantes de la obra. ${ }^{20}$ No obstante; estas producciones con sus indiscutibles aportes están atravesadas por, al menos, dos directrices prefijadas por Alberto Palcos. Primero, la atención puesta sobre el recorrido póstumo del Facundo; segundo, la necesidad de repensar el escrito con el objetivo de lograr una edición crítica capaz de reemplazar a las originales. Veamos esto mediante dos ejemplos.

Guillermo Ara (1958) abordó las variantes a la escritura en las versiones librarias. Para este estudioso era necesario volver sobre la historia del Facundo por que las alteraciones hechas por el autor resultaron tan complejas que Palcos no infirió algunas. La labor de Ara sumó nuevos conocimientos, uno de ellos fue la contabilización que realizó de las ediciones pos Sarmiento; para el investigador, dentro de ese grupo, el libro configurado por Palcos en 1938 superaría "con ilimitado margen" a los demás (p. 391). De tal manera, refleja Ara la atención prestada a las publicaciones póstumas con el objetivo de lograr efectuar un Facundo canónico.

Por su parte, Garrels (1988) examinó El Progreso para demostrar, entre otras cuestiones, que el primigenio Facundo habría llegado hasta el capítulo "Barranco Yaco!!" Pero Garrels revela algo más, si bien destaca la necesidad de consultar las fuentes originales en el estudio de las ediciones, para contrastar los cambios con el libro la investigadora utiliza el Facundo de Ediciones Culturales Argentinas (Sarmiento, 1961). ${ }^{21}$ Por ende, la participación de Garrels no se reduce únicamente a exponer la importancia del folletín, además consagra la versión actualizada por sobre las originales para indagar la obra.

Volviendo a la hipótesis planteada al comienzo, los autores citados permiten advertir que indagaron la historia del Facundo como publicación y, además, actuaron para consagrar una edición canónica. Tal estado de la cuestión me lleva a explorar las versiones póstumas conjeturando que estas adaptaciones hechas al Facundo transformaron el contenido sarmientino según los nuevos intereses editoriales.

dichos escritores del siglo xIx para mostrar que el sanjuanino estuvo a la altura de las figuras consideradas entre los padres de la literatura nacional.

${ }^{20}$ Entre estos trabajos podemos distinguir: Ara (1958); Cabo y Nijensohn (2012); Carilla (1959); Garrels (1988); Gowa (1948); Moglia (1955); Pagliai (2012); Scarano (2012); Tacca (2000), etcétera.

${ }^{21}$ Este ejemplar es una reedición del libro preparado por Palcos en 1938. 


\section{LA TRAYECTORIA PÓSTUMA DEL FACUNDO}

\section{Facundo en la primera mitad del siglo $\mathrm{xX}$}

Inmediatamente luego del deceso de Sarmiento comienza la modificación del Facundo por parte de distintos trabajos editoriales. ${ }^{22}$ Las primeras publicaciones fueron Facundo o civilizacion i barbarie (Sarmiento, 1888-1889), ${ }^{23}$ Quiroga, Aldao, el Chacho 1845-1863 (Sarmiento, 1889a), ${ }^{24}$ Civilizacion i barbarie. Vidas de Quiroga, Aldao y el Chacho (Sarmiento, 1889b), ${ }^{25}$ Civilizacion y barbarie (Sarmiento, 1896). ${ }^{26}$

¿Qué posibilitan observar las características de las ediciones póstumas? Advierto que los editores encontraron diferencias para acordar un libro. Los ejemplares de Montevideo (Sarmiento, 1888-1889) y Santiago de Chile (Sarmiento, 1889a) buscaron aproximarse al Facundo de 1845 y 1851. En cambio, Lajuane (Sarmiento, 1889b) y Belín Sarmiento (Sarmiento, 1896) apuntaron a volver a la versión final (Sarmiento, 1874). Esas disparidades representan una cuestión clave: la apropiación de la obra por las diversas empresas editoriales, la muerte de Sarmiento abrió en las postrimerías del siglo xIx la lucha por

${ }^{22}$ En este apartado comentaré las ediciones que considero sustanciales para comprender la historia del Facundo posSarmiento. Las del siglo xix porque son las que inicialmente aparecen una vez muerto el autor, la de Biblioteca "La Nación" debido a que es la primera publicada en el siglo xx, las de Palcos $(1938 ; 1961)$ y Biblioteca Ayacucho (1977) porque son la más consultadas actualmente.

${ }^{23}$ Versión configurada en Montevideo, impresa en formato de bolsillo y dividida en tres tomos, uno fechado en 1888 y los restantes en 1889. Articula el contenido de 1845 y 1851: carta de Alsina, introducción de 1845 y Quiroga. Los editores colocaron una nota en el texto indicando que no compartían las ideas vertidas en torno a la independencia de Uruguay y de dos figuras políticas: Gervasio Artigas y Fructuoso Rivera.

${ }^{24}$ Tomo vil de Obras, preparado por Luis Montt y aparecido en Chile. Integra Quiroga, Aldao y el Chacho, si bien el modelo del tomo vil se asemeja al de 1874, esto no significó que Montt haya seguido la lógica de la última edición sarmientina. El editor chileno compiló según el tema -"caudillos"- las biografías de Quiroga, Aldao y Peñaloza y por ello aplicó un título tan particular. Además Montt agregó un elemento ajeno a Quiroga -la carta a Matías Callandrelliy uno a Aldao: "Testamento de Aldao".

${ }^{25}$ Libro a cargo de Lajouane, sigue la estructura de Obras. Agrega un frontispicio de Sarmiento; además suma los retratos de Quiroga, Rosas, Aldao y Peñaloza. Por el título que aplica, modifica la lógica editorial de Montt ya que, al considerar a los tres textos-Quiroga, Aldao y el Chacho- parte del Facundo, asemeja su libro al último que preparó Sarmiento en 1874.

${ }^{26}$ Reedición del tomo vil de las Obras. El editor cambió, en esta oportunidad fue Belín Sarmiento. Continúa con la línea editorial de Lajouane, consistente en asimilar el tomo al Facundo de 1874. 
imponer un Facundo. ${ }^{27}$ Esto se acentuará aún más con las transformaciones contextuales que traerá la centuria siguiente.

En los albores del siglo xx las elites dirigentes tuvieron el gran desafío de afrontar la "cuestión social", emergida a partir de la llegada de inmigrantes, la organización obrera y el surgimiento de posiciones políticas que cuestionaban el statu quo imperante. La solución, en parte, consistió en repensar el "ser" argentino "diluido" ante la marea inmigratoria y los pensamientos importados - principalmente el anarquismo-que "intoxicaban" a la población, con ese fin se apeló a reinterpretar el pasado: "Esa relectura debía consistir en la búsqueda de los rasgos permanentes de la propia cultura con los que enfrentar el cosmopolitismo. No los rasgos inciertos de algo que se habrá de construir en el futuro sino aquellos ya definidos, que se conservan inmodificados en el fondo de la historia" (Bertoni, 2007, p. 165).

Partiendo de esa premisa, parte de la intelectualidad, imbuida en las ideas del positivismo de la época, apelará a configurar una nacionalidad recurriendo a "las fuerzas morales" (Terán, 2000, p. 339). El método seleccionado para instaurar una moralidad capaz de guiar la patria no fue otro que el ya concebido por las generaciones liberales antecesoras: "la educación pública y ahora animada de un núcleo fuertemente patriótico" (Terán, 2000, p. 342). En síntesis, la elite dirigente dio origen a la "educación patriótica", ideada para fortalecer y cuidar a la nación de aquellos agentes externos que la perjudicaban. Enseñando en las aulas lo que estaba bien y lo que era pernicioso para la patria, qué valores debían seguirse -amor al país y la familia, apego al trabajo, etc.-, la "educación patriótica" definía e imponía la moral por la cual debía regirse la sociedad argentina.

Ineluctablemente, en la instauración de la educación patriótica, será impulsada la lectura bajo clave moral. Entre los títulos seleccionados se encontraba el Facundo, con ese fin aparece la primera edición del siglo xx a cargo de Biblioteca de "La Nación". ${ }^{28}$ Los textos pensados por los editores seguirán

${ }^{27}$ No obstante, vale destacar que pervivió en los cuatro libros una lectura política por parte de los diversos editores. Por este motivo, por ejemplo, quienes publicaron al Facundo en Montevideo tomaron recaudos para aclarar su distanciamiento respecto a los comentarios de Sarmiento en torno a Artigas y Rivera.

${ }^{28}$ Biblioteca de "La Nación" fue un proyecto editorial que buscaba imprimir ejemplares a bajo costo para alcanzar un público amplio. Patricia Willson (2004) define a la colección de la siguiente manera: "Primera conjunción empresa periodística-libro del siglo xx, en la que un diario se sirve de un 'fondo editorial' para generar lectores en la Argentina” (pp. 47-48). 
con los lineamientos fijados para formar argentinos patriotas, pues compartían el lamento "por las malas lecturas populares" y, en respuesta, reafirmaban "la necesidad de enderezar el gusto por las publicaciones supuestamente amorales o antiestéticas: necesidad de educar a las masas, de fomentar la "intelectualidad nacional'" (Merbilhaá, 2014, p. 36). ${ }^{29}$

Esta versión apareció en 1903 bajo el título Facundo, integra la introducción -"Sombra terrible de Facundo..."-, los quince capítulos de Quiroga y el apéndice con las proclamas del riojano. En los albores del siglo xx se intentaba volver a las tres primeras presentaciones: empleando el título del folletín, el contenido del libro de 1845 y las proclamas de 1851. La estructura de este ejemplar privilegia un tipo de lectura: el "caudillismo" como el mal gobierno y, en respuesta a esto, los liberales representando la solución a esos problemas políticos.

Además, se enaltecía lo singular de la naciente literatura argentina, así lo expresaban los responsables intelectuales de este libro: "Facundo, como se llama generalmente y como fue el primer título de la obra de don Domingo Faustino Sarmiento, es un libro argentino en toda la extensión de la palabra, un libro genuinamente nacional" (Sarmiento, 1903, p. III).

En cuanto a las partes, ¿cuál fue el motivo que llevó a los editores de La Nación a recortar el último Facundo preparado por Sarmiento? En el prólogo argumentaban: "hasta hoy no se había publicado una edición realmente popular que estuviera bien al alcance de todo el mundo y que se difundiera por el país entero. Al contrario, todas las ediciones, inclusive la que figura en las Obras completas, son costosas, y sólo esta última no está agotada todavía" (Sarmiento, 1903, p. IV).

Abreviando, el móvil principal para la nueva versión se hallaba en el agotamiento de los ejemplares originales. Ahora, la fundamentación para acotar el contenido seguía las disposiciones que sustentaban la colección: lograr un tomo no muy costoso para, de esa manera, alcanzar un vasto público. El prólogo explicitaba la intención de romper con las barreras culturales para hacer llegar el Facundo más allá de los típicos grupos letrados: "de hoy en más, Facundo figurará, no sólo en los estantes de las bibliotecas de las ciudades, sino también hasta en los anaqueles de los ranchos de campaña, llenando, por fin, en toda su amplitud, el papel que le estaba señalado desde que brotó

${ }^{29}$ Es preciso aclarar que este Facundo no se piensa específicamente para las escuelas, pero integra los escritos considerados necesarios para formar a la población argentina. 
de la inspirada pluma de su autor" (Sarmiento, 1903, p. IV). En conclusión, Biblioteca de "La Nación" ideó el libro atendiendo el equilibrio entre costo y necesidad político-cultural. ${ }^{30}$

Resumiendo, en los albores del siglo xx comienza a trasladar la función del Facundo propia del campo político, para el cual lo pensó el autor sanjuanino, a uno educativo. Pero, es preciso destacar, no se pierde lo político, sino que convive con otros aspectos. Esta forma de entender la obra sarmientina será retomada en la década de 1930 cuando Palcos concrete su edición según nuevos requerimientos intelectuales.

El Facundo de Palcos apareció dentro del marco histórico caracterizado por la crisis del modelo agroexportador y los replanteos en torno al sistema democrático surgido a partir de la ley Sáenz Peña (1912) y la llegada del radicalismo al poder. Habían pasado ya casi diez años del derrocamiento de Hipólito Yrigoyen y, para los círculos intelectuales de la época, una de las principales causas y consecuencias de ese hecho radicaba en "la cuestión de la viabilidad y conveniencia del régimen democrático” (Falcón, 2000, p. 345). En los debates vigentes, sostenidos por los distintos actores políticos e intelectuales nuevamente se apelaba a la historia para explicar las problemáticas que acuciaban al modelo político y económico de entonces. Dentro de esa vorágine "En materia de estudios históricos, los gobiernos de la década pusieron especial énfasis en elaborar una liturgia patriótica compuesta por celebraciones, monumentos, identificación de lugares históricos y fijación de efemérides; con ello continuaban demandando servicios a la Historia ahora bajo una fórmula: 'fortalecimiento de la conciencia nacional'" (Devoto y Pagano, 2010, p. 171). ${ }^{31}$

En consecuencia, el Estado reimpulsará una solución desde la instrucción escolar para actuar sobre la moral. Recurriendo otra vez al rol morali-

30 Al parecer el éxito de la edición fue notable, a la vista está que Biblioteca de "La Nación" realizó nuevos tirajes en 1906, 1909, 1910 y 1911.

${ }^{31}$ Para Diana Quattrocchi-Woisson (1995) "la oficialización del saber histórico y el control del Estado sobre la memoria colectiva toman en esta época una amplitud extraordinaria. Objeto de una reglamentación institucional sin precedente, la Historia se vuelve una verdadera cuestión de Estado. La institucionalización del saber histórico otorga a la historia un lugar privilegiado en un dispositivo tendiente a controlar cada vez más la memoria nacional” (p. 141). No es casualidad que en la década de 1930 hayan surgido prestigiosas instituciones historiográficas como la Sociedad de Historia Argentina (1931), la Academia Nacional de la Historia (1938) y el Instituto de Investigaciones Históricas Juan Manuel de Rosas (1938) (Devoto y Pagano, 2010, pp. 173-174). 
zante de la historia, diferentes medidas tendieron a regular el dictado de la materia en las escuelas. Alberto Palcos integró el grupo de figuras que debatieron sobre la importancia de la historia para la sociedad y, particularmente, para el ámbito escolar. ${ }^{32}$ Desde esta perspectiva el estudioso de las ediciones prepararía un Facundo con tinte educativo y moral. Veamos de qué manera.

Primero, el editor continuó utilizando el título Facundo para desde allí centrar el problema de la obra en la cuestión de los "caudillos" y sus prácticas negativas en la política. A través de Sarmiento, Palcos indicaba qué no debían hacer los argentinos patriotas, al mismo tiempo sumó otro aspecto clave para fortalecer la argentinidad: la literatura, destacando la excepcionalidad de las letras nacionales según el estilo que el sanjuanino estampó en el Facundo. ${ }^{33}$ Sintetizando, Palcos interviene en el campo educativo añadiendo la importancia de conocer la cultura propia a través de la literatura argentina.

La diferencia del Facundo de 1938 con los anteriores es que este aparece en un momento donde el Estado argentino, sirviéndose del mecanismo montado durante décadas previas, estaba decidido a intervenir con mayor intensidad en la formación patriótica. Recapitulando, la proyección de Palcos apuntó en dos caminos. En líneas generales, para satisfacer los requerimientos intelectuales de la década de 1930. Al mismo tiempo, y siguiendo con las demandas culturales del momento, daría un paso más al aplicar una serie de recursos destinados a captar un público estudiantil avanzado ya que es una edición crítica. ¿Cómo se pensó el contenido para satisfacer los diversos objetivos?

El título fijado es Facundo, el ejemplar comienza con el "Anuncio de la "Vida de Quiroga", "Advertencia del autor", prólogo -"A fines del año 1840..."-, introducción y la carta remitida a Valentín Alsina. La estructura del libro integra los quince capítulos de Quiroga y el apéndice con las proclamas. En el texto se enseñan las correcciones que Sarmiento fue realizando, sobre todo en 1851. Entre las páginas figuran imágenes intercaladas: de los personajes típicos pintados en el relato, las portadas de las ediciones, retratos de Sarmiento, Alsina, Quiroga, Lavalle, Rivadavia, etc. El editor complementaba los capítulos

32 Por ejemplo, en 1937 Palcos participó en el II Congreso Internacional de Historia de América, donde expuso sus ideas y propuestas referidas a la enseñanza de la historia en los colegios (Cataruzza, 2001, p. 458).

${ }_{33}$ Palcos no es el primero en destacar el vínculo de la literatura con la formación de la patria. Al contrario, previamente Ricardo Rojas y José Ingenieros, con disímiles lineamientos, pensaron colecciones editoriales para cimentar una tradición literaria y, desde allí, dar forma a la cultura nacional (Degiovanni, 2008). 
con un amplio apartado: "Documentos relacionados con el Facundo". 34 Por último, vale apuntar, si bien Palcos seguía la edición de 1874, interfería mediante la supresión de las biografías de Aldao y Peñaloza. Las semblanzas que Sarmiento había decidido insertar para acompañar a Quiroga eran eliminadas definitivamente.

Respecto al rol educativo del libro: ¿De qué manera reflejan estas características la búsqueda de un público estudiantil? Para empezar, el nombre Facundo, al igual que en 1903, simplifica la recepción. Dejar de lado el sintagma "Civilización y barbarie" significaba presentar una historia no atravesada por la complejidad que dicha fórmula impregnaba en la explicación de la sociedad y "caudillos" argentinos donde todos los protagonistas -como el mismo Quiroga- son civilizados y bárbaros. Desde allí se comprende la opción por suprimir Aldao y el Chacho, escritos que extendían y hacían más densa la narración y consiguiente lectura. Además, las imágenes implicaron el uso de recursos didácticos para graficar el relato sarmientino.

Por todo esto, la operación de Alberto Palcos para llevar el Facundo al plano moral difirió de la de Biblioteca "La Nación". El cambio de coyuntura provocó una asignación de funciones más incisivas, de ahí los objetivos de la edición de 1938 apuntando a formar patriotas conocedores de su literatura, historia, costumbres, etc. Volviendo al trabajo del editor, basó fundamentalmente su meticuloso estudio en la recuperación de las rectificaciones concretadas por el autor para el libro de 1851. Examinemos sucintamente en qué consistió el trabajo crítico.

La edición de 1938 apareció bajo el marco de la Biblioteca de Autores Nacionales y Extranjeros referente a la República Argentina. Conformó el primer tomo de la entrega; el segundo fue el Dogma Socialista de Esteban Echeverría -publicado en 1940-. Según indica Palcos, la preferencia por el Facundo para iniciar la serie se debió a que

constituye el primer libro argentino que suscita verdadera resonancia en las letras mundiales; cuatro idiomas sabios lo traducen. Por su agencia adquieren universalidad literaria la Pampa y el Gaucho, Quiroga y Rosas. Sarmiento

${ }^{34}$ Entre los textos que lo componen sobresalen: "Nota de Valentín Alsina al libro 'Civilización i barbarie"; "Civilización y barbarie. Del americanismo i de las repúblicas del Sur.- La sociedad arjentina.- Quiroga.- Rosas.- Revue de Deux Mondes, 15 de septiembre de 1846, por Charles Mazade", "carta Al profesor don Matías Callandrelli" y "Prefacio. De la traducción inglesa por Mrs. Horace Mann”. 
percibe la originalidad de nuestra naturaleza y de los tipos que engendra y los lleva a su libro. En lugar de imitar lo extraño, revela un mundo nuevo, bárbaro y primitivo aún, pero lleno de grandiosidad y de poesía (Palcos, 1938, pp. XIII-XIV).

Palcos presentaba un libro netamente argentino, su lectura destacaba los aspectos que hacían al Facundo un claro exponente de la cultura nacional; es decir, para lograr que significara un título para la educación de "patriotas", el editor necesitó de una operación complementaria: convertirlo en texto propio de la literatura argentina. ${ }^{35}$ Bajo ese criterio, la revisión para la publicación de 1938 buscó quitar todos los elementos juzgados perniciosos para la presentación de un escrito que se pretendía consagrar dentro de las letras nacionales. ¿De qué modo Palcos desplegó su labor crítica? Básicamente tomó como referencia la versión de $1874^{36}$ y desde allí señaló los cambios realizados por Sarmiento en 1851 -principalmente- y 1868, incluyó además una comparación con la edición de las Obras. ${ }^{37}$

Palcos, notablemente, expuso las variaciones de determinadas palabras u oraciones. Sin embargo, mediante una lectura comparada entre el libro de 1874 y el de 1938, logré detectar la prevalencia de otras modificaciones aplicadas por él mismo y que no contaron con ningún tipo de aclaración para tenerlas en cuenta o precisar el porqué del cambio. En otras palabras, la labor del editor transcurrió más allá de la mera comparación. Sea mediante el uso de signos de puntuación, cambio de palabras o alteraciones de oraciones, el estudioso puso su impronta para reformar el relato. Para decirlo de una vez,

${ }^{35}$ La cuestión de literatura y educación para definir la argentinidad fue algo que atravesó el pensamiento de Palcos en esta colección; así, por ejemplo, en el prólogo al El Dogma Socialista el editor destacaba las contribuciones literarias de Echeverría: "Como poeta presta dos grandes servicios a las letras del Plata: introduce la revolución romántica y, gracias a la mentada CAUTIvA, incorpora el paisaje nacional como tema de inspiración literaria. Señala, de tal suerte, rumbos en la América Latina: en adelante los artistas e intelectuales, si desean dar una nota propia y ser algo dentro de las letras mundiales, deberán dejar de lado la imitación servil y dedicarse a captar las peculiaridades del medio y de los tipos neocontinentales" (Palcos, 1940, p. XVIII).

36 "En los trabajos antes recordados [refiere a El Facundo (1934) y algunos escritos periodísticos destinados también a marcar los errores del volumen viI de las Obras] indicábamos la edición de París, la última aparecida durante la existencia de Sarmiento, como base de una buena reedición, despojándola, desde luego, mediante el cotejo con las precedentes, de los pequeños lunares que presenta" (Palcos, 1938, p. XXII).

${ }^{37}$ En otras notas, señalaba Palcos la influencia de Alsina sobre Sarmiento al momento de efectuar arreglos particulares. 
en 1938 Alberto Palcos reescribe el Facundo, la obra ya no pertenece a Sarmiento sino a este reconocido erudito. Esta hipótesis la desarrollaré mediante los siguientes casos en los que Palcos interviene sin ningún tipo de explicación que fundamente la corrección.

En la edición de 1874, Sarmiento afirmaba sobre la infancia de Quiroga: "en la escuela era altivo, uraño y solitario; no se mezclaba con demas niños sino para acaudillarlos en actos de rebelión” (Sarmiento, 1874, p. 51). Palcos permuta "acaudillarlos" por "encabezarlos"; en esta oportunidad aplicaba el término utilizado en las ediciones de 1845 y 1851, pero no realizaba ninguna llamada para señalar la variación. ${ }^{38}$ La injerencia buscaba disminuir la intensidad del relato, amenguando el espíritu de "caudillo" mostrado desde su infancia por Quiroga. ¿La razón? Posiblemente el editor no quería que en un texto dirigido a los estudiantes se expusiera a los niños con rasgos propios de un "salvaje".

Incluso, para hacer más amena la consulta, alteró los signos de puntuación. En algunas oportunidades agregó comas, puntos o dos puntos con el fin de lograr una lectura más ágil. Por ejemplo, la edición de 1874 expresa: "La Junta había llamado al Gobernador con instancia, para que desde allí, i con apoyo de todos los ciudadanos invadiese los Llanos i desarmase a Quiroga" (Sarmiento, 1874, p. 66). Palcos modifica de la siguiente manera "La Junta había llamado al Gobernador, [agrega coma] con instancia, para que desde allí, i con apoyo de todos los ciudadanos, [agrega coma] invadiese los Llanos i desarmase a Quiroga" (Sarmiento, 1938, p. 110).

Si el Facundo estaba destinado a leerse en las aulas y convertirse en estandarte de las letras argentinas, su consulta tenía que ser clara y gustosa. En esa dirección apuntó el editor. La supresión de las vidas de Aldao y Peñaloza, más los ejemplos citados de Quiroga denotan que Palcos reescribió el Facundo. El notable trabajo crítico que desplegó no sólo buscó recuperar las transformaciones desarrolladas por Sarmiento en las cuantiosas versiones. Su labor apuntó a presentar un contenido propio para el público del siglo xx. Palcos se adueña de la obra para intervenir en el campo educativo, histórico y, principalmente, literario.

La acción editorial de Palcos tuvo notable éxito ya que consigue canonizar al Facundo de 1938 como la mejor versión, en adelante la mayoría de

38 Llamativamente este cambio también fue efectuado en Obras (Sarmiento, 1889a), exhibía así Palcos una similitud con el tan vituperado criterio de Montt. 
los estudiosos lo utilizarán como fuente de consulta y, además, las nuevas presentaciones seguirán este modelo. Incluso, en 1961 Ediciones Culturales Argentinas efectuó una segunda edición, también muy consultada por los investigadores. Este libro apareció bajo los auspicios del gobierno, específicamente de la Dirección General de la Cultura. Entonces la nueva presentación implicaba una lectura oficial del Facundo, en particular, y la obra de Sarmiento, en general. ${ }^{39}$

\section{Facundo en la segunda mitad del siglo $\mathrm{xx}$}

Fueron tiempos políticos agitados donde se buscaba estabilidad luego del derrocamiento de Juan Perón en 1955 y la consiguiente proscripción del peronismo. Arturo Frondizi logró ganar la presidencia en 1958 y puso en marcha un proyecto gubernamental desarrollista donde la modernización de los diversos sectores conformaba uno de los pilares fundamentales de la gestión. ${ }^{40}$ Dentro del ámbito intelectual, parte del debate giraba en torno al peronismo, en cómo explicar ese nuevo fenómeno de la historia argentina.

El debate tomaría vigor dentro de la universidad, donde la sociología "desempeñó un papel altamente significativo por el modo en que modificó el abordaje de los fenómenos nacionales” (Terán, 2012, p. 276). La sociología tuvo función relevante al momento de repensar la Argentina posPerón: "Era un espacio donde se dirimían visiones del pasado histórico nacional, un lugar en el que se resignificaba una genealogía de referentes culturales" (Rubinich, 2003, p. 250). La disciplina traía nuevas respuestas a las apetencias históricas de la sociedad..$^{41} \mathrm{El} \mathrm{Facundo} \mathrm{de} 1961$ evidencia ese impacto de la sociología. No es casualidad que en la presentación del ejemplar, realizada por Mauricio Rosenthal, se fijara una lectura sociológica. Rosenthal afirmaba que este título sarmientino conformaba un "libro fundamental de la hermenéutica y socio-

${ }^{39}$ Esta edición pertenece a una colección de libros, seis en total, donde se compilaban cartas de Sarmiento y algunos escritos públicos, como la Vida de Dominguito; Facundo fue el primer tomo de la colección.

${ }^{40}$ Fruto de tal impulso modernizador, aparecieron instituciones como el CONICET, Eudeba y el Fondo Nacional de las Artes.

${ }^{41}$ La economía también tuvo aportes considerables para entonces en la renovación de los estudios históricos. Incluso para Devoto y Pagano "En muchos sentidos, la historia económica constituía por entonces el territorio en el que es más factible la colaboración de los historiadores con las nuevas ciencias sociales" (Devoto y Pagano, 2010, p. 415). 
logía argentina”. A comienzos de los años sesenta la obra adquiría rasgos de cientificidad.

Palcos nuevamente estuvo a cargo de la edición, las diferencias de contenido con la de 1938 son las siguientes: quita varias imágenes y agrega algunas misivas dirigidas a Sarmiento. Buscando reforzar el aspecto científico, en detrimento de los recursos didácticos se ampliaba el aparato documental. Y no sólo esto, además, respecto a la versión de 1938, el crítico volvió a aplicar algunas modificaciones en la redacción. En otras palabras, Palcos reescribía el Facundo de Palcos. Es decir, para el mismo editor no perduró un texto definitivo ya que nuevamente lo corrigió.

Las variantes de grafía y conceptuales evidencian cierta disconformidad con el libro de 1938. Incluso en la puntuación otra vez Palcos necesitó precisar cambios. ${ }^{42}$ Más allá de que sean pocas las alteraciones entre la publicación de 1938 y 1961, estos muestran que en el mismo editor no perduró un criterio definitivo al momento de precisar la presentación. En la segunda mitad del siglo xx continuaba reescribiéndose el Facundo, y lo que denotan las variaciones más frecuentes es la búsqueda por lograr un texto con la mayor riqueza literaria posible. Vale decir que, al Facundo, ya sea para una lectura escolar o sociológica, las ediciones coinciden en que buscan consagrarlo en la literatura Argentina.

Por último, quiero detenerme en la versión publicada por la Biblioteca Ayacucho, ya que también será asiduamente consultada por los estudiosos, veamos en qué consistió este libro. La Biblioteca agrupa sus publicaciones en diferentes secciones, dentro de las mismas, el Facundo integra la "colección clásica". Los editores indican que "colección clásica" está conformada, en parte, por "las publicaciones de autores que han merecido el reconocimiento universal y cuyo hacer literario ha constituido la formación de vanguardias en el mundo". El Facundo compone una biblioteca de carácter continental, la obra atraviesa los límites nacionales. Al mismo tiempo, esa consagración se basa en la faceta literaria del texto. Indaguemos esto en las características de la edición.

${ }^{42}$ Por ejemplo, Sarmiento escribía: "Pero lo que hai de averiguado, es que su padre pidio una vez al Gobierno de la Rioja que lo prendieran para contener sus demasías, i que Facundo, antes de fugar de los Llanos, fue la ciudad de la Rioja donde a la sazón se hallaba aquel" (Sarmiento, 1874, p. 55). Palcos rectifica: "Pero lo que hai de averiguado, es que su padre pidio una vez al Gobierno de la Rioja que lo prendieran para contener sus demasías [suprime coma] i que Facundo, antes de fugar de los Llanos, fue la ciudad de la Rioja donde a la sazón se hallaba aquel" (Sarmiento, 1961, p. 86). 
Apareció en 1977, el título es Facundo, cuenta con un prólogo de Noé Jitrik y anotaciones de Nora Dottori y Susana Zanetti (Sarmiento, 1977). Este libro, según aclaran Dottori y Zanetti, sigue al de Universidad Nacional de La Plata (1938) "con la salvedad de que hemos modernizado la grafía -muy personal en Sarmiento- y la puntuación" (Dottori y Zanetti, 1977, p. LIV). Además, en los capítulos se brindan notas aclaratorias en torno al contexto político e ideológico. Biblioteca Ayacucho también apunta a mejorar la redacción, basándose en los comentarios de Alsina y en la actualización de la grafía.

Las particularidades de la edición me permiten llegar a dos inferencias. Por un lado, es destacable la relevancia de las versiones de Palcos. El Facundo de 1938 es tomado como una continuidad de las presentaciones sarmientinas, por eso se sigue ese libro. Por otra parte, los editores de Biblioteca Ayacucho igualmente reescriben el Facundo, al optar por actualizar la grafía diferencian la escritura de aquella desarrollada por el sanjuanino en tiempos decimonónicos, exhibiendo así la impronta del siglo xx.

¿Por qué es importante tener presente la historia del Facundo desde Sarmiento hasta sus editores póstumos? Esta respuesta requiere sumar otro punto a mi exposición. En el mismo, según procuraré evidenciar, puede observarse cómo el entendimiento en cuanto al contenido del Facundo varió entre la última edición preparada por el autor en 1874 y la que logró consagrar Palcos. Para efectuar este objetivo, compararé lecturas concretadas antes del Facundo canónico (1938) con otras realizadas luego de su publicación.

\section{LECTORES PREVIOS Y POSTERIORES AL FACUNDO DE PALCOS}

\section{La recepción antes del Facundo canónico (1938)}

Juan B. Alberdi redactó El Facundo y su biógrafo y, aunque no llegó a publicarlo, ${ }^{43}$ constituye una sugerente lectura del último Facundo (1874). La estrategia de Alberdi residió en utilizar argumentos cientificistas, pero no pretendiendo llegar a una verdad de los hechos sino apuntando a desprestigiar a Sarmiento, quien para la fecha había o estaba a punto de dejar el mandato presiden-

\footnotetext{
${ }^{43}$ El Facundo y su biógrafo apareció, junto a Belgrano y sus historiadores, en el quinto tomo de los Escritos póstumos (1897).
} 
cial. Entre los cuantiosos puntos refutados por Alberdi, quiero detenerme en aquellos donde recusa los fundamentos del Facundo con base en las tres semblanzas que lo integraron en 1874: Quiroga-Aldao-el Chacho. Desde ese enfoque, basándose en la heterogeneidad de los textos de la cuarta edición libraria, el tucumano apuntaba incoherencias en el pensamiento del sanjuanino. Veamos de qué forma arguyó.

En primer lugar, imputó de plagio a Sarmiento. Para Alberdi en la misma estructura de la obra se hallaba la respuesta: “¿Por qué lleva el nombre de El Facundo el volumen que contiene varias obras? Porque el Facundo es la mejor de las obras firmadas por Sarmiento. Basta compararla con las otras para reconocer que la pluma no es la misma" (Alberdi, 1897, p. 274). Sin ahondar en la veracidad de su afirmación, me interesa destacar la manera de leer del tucumano: el Facundo de 1874 abarca más de una biografía, y entre los escritos pueden apreciarse radicales disparidades de estilos que denotarían la pluma de, al menos, dos autores.

En segundo lugar, Alberdi no tenía reparos en acusar a Sarmiento de "bárbaro". La violencia ejercida por el sanjuanino desde sus publicaciones, y también mediante el poder político, lo habían convertido a los ojos de Alberdi en un "caudillo". La integridad del último Facundo traslucía la naturaleza violenta del exgobernador de San Juan: "Mientras el autor pretende haber escrito el proceso de los caudillos, el libro demuestra que ha escrito el manual de los caudillos y del caudillaje" (Alberdi, 1897, p. 294). Agregaba el tucumano: "Si Sarmiento es uno de los autores de su libro, también es uno de los héroes que su libro encierra. Es, sin duda alguna, un personaje histórico al mismo tiempo que lo son Rosas, Quiroga, Aldao, Peñaloza, y todos los caudillos que él mismo ha considerado dignos de la historia cuando se ha dado el trabajo de estudiar y escribir sus vidas" (Alberdi, 1897, p. 364).

¿Qué expone la lectura alberdiana? Para el objetivo de mi trabajo, la recepción del autor de Bases (1952) es clave porque, más allá de la operación política que estaba efectuando, exhibe que el Facundo de 1874 era concebido como un libro integrado por tres semblanzas de "caudillos". Vale decir, si Alberdi llega a cuestionar la incoherencia interna del último Facundo, esto se debe a que la fuente que consulta le permite fundamentar sus afirmaciones en base a los estilos disímiles que presentan sus partes: Quiroga-Aldao-el Chacho. Avancemos sobre el siguiente lector: Ricardo Rojas. 
Ricardo Rojas plasmó su lectura del Facundo en la edición de 1916, perteneciente a la Biblioteca Argentina ${ }^{44}$ Para este escritor e intelectual, con el fin de mostrar la existencia de una literatura nacional, la importancia fundamental de la obra radicaba en su aporte a las letras. ${ }^{45} \mathrm{Si}$ bien Rojas manifestaba la necesidad de despojar al Facundo de toda connotación política, con su exposición en realidad estaba discutiendo dentro de ese campo sobre la forma de entender la nación.

Según Rojas, Facundo apareció como texto político, de combate contra Rosas. Pero, al ser pensado para la centuria pasada, en el siglo xx no tenía vigencia. Principalmente este estudioso quería argumentar que el planteo nodal de la obra, "civilización y barbarie", resultaba obsoleto para los tiempos en curso. ${ }^{46}$ La colección apuntaba a rescatar todos los aspectos considerados propios de la cultura argentina, por este motivo priorizaba superar el sintagma aplicado en el Facundo donde se definía que era bueno o malo para el país. Según razonaba el erudito tucumano, si era "criollo" pertenecía a la cultura nacional. Partiendo de esta premisa, cabe la pregunta ¿De qué manera leyó Rojas el Facundo para llegar a sus conclusiones?

Siempre enfatizando en lo literario, pondera el aporte del texto sarmientino en cuanto al conocimiento que brindó sobre la Argentina, mediante las distintas traducciones, al resto del mundo. Por otra parte, con el afán de analizar sus rasgos políticos, repasa la historia de la publicación. Rojas decide usar como fuente el tomo vir de las Obras preparado por Belín Sarmiento. El motivo de dicha selección se debe a que el intelectual asimiló a este Facundo como un equivalente al de 1874. Partiendo de esa consideración, afirma: "En la edición de 1874 (París, Háchete, 4a. edición castellana) el libro comprendía ya las tres biografías o vidas de Quiroga, Aldao y el Chacho, como aparece en el volumen vir de las Obras Completas" (Rojas, 1916, p. 2).

${ }^{44}$ El cuerpo de esta versión únicamente se compone de la vida de Quiroga -quince capítulos-. En un apéndice se agregan las proclamas del riojano, la carta a Matías Callandrelli, la introducción de 1845 y la carta prólogo remitida a Valentía Alsina.

${ }_{45}$ "A las intuiciones de su autor como artista, debió este libro su éxito extraordinario, desde el día de su aparición [...] Por eso lo tradujeron a diversos idiomas, para dar a otras gentes la visión de nuestra vida pampeana, y mostrar en la raíz del desierto el germen de nuestras luchas. Por eso se han desprendido del volumen, como páginas de antología popular, las siluetas del Rastreador, del Baqueano, del Gaucho malo y del caudillo silvestre" (Rojas, 1916, p. 24).

46 "Esta fórmula ha prestado sus servicios al progreso del país, pero es tiempo ya de comenzar a denunciarla por lo que tiene de parcial y de peligrosa” (Rojas, 1916, p. 22). 
Ricardo Rojas indagó al Facundo desde su trayectoria editorial con un doble objetivo. Primero, para aclarar que los diversos cambios sufridos hasta el libro final de 1874 no hicieron otra cosa que ampliar el relato en torno a los "caudillos" y la cuestión "civilización y barbarie". Segundo, esto último le permitía fundamentar por qué su consulta estuvo acotada a ciertas páginas del cuarto Facundo librario: "Nosotros no damos aquí sino la Vida de Facundo, pues forma parte del paisaje descripto y de la doctrina esquematizada en esos términos; "Civilización y Barbarie"” (Rojas, 1916, p. 22). En otras palabras, optó solamente por Quiroga debido a que la tesis central que el intelectual intentaba rebatir principalmente se encontraba en esta biografía. ${ }^{47}$

¿Qué tienen en común un lector del siglo xIx - Alberdi-y uno del xx -Rojas-? Por un lado, coinciden en frecuentar al Facundo definitivo, es decir el de $1874 .{ }^{48} \mathrm{Al}$ mismo tiempo, ambas figuras comparten con base en la fuente un entendimiento común en cuanto a las partes del contenido: Facundo desde la última versión preparada por Sarmiento se integraba por Quiroga-Aldao-el Chacho. Para finalizar resta avanzar sobre la recepción luego de la edición de Palcos, de este modo podremos ver qué tipo de lectura se impuso desde 1938.

\section{La recepción después del Facundo canónico (1938)}

Con el fin de estudiar la temática "caudillo" y "caudillismo" en la época de Rosas, Jorge Myers (1998) utilizó al Facundo como una de sus fuentes principales. El trabajo de este investigador, fiel a la propuesta, hace dialogar a Sarmiento con algunos contemporáneos como Herrera y Obes para cruzar las diferentes maneras de interpretar el fenómeno. Para Myers (1998), respecto a la distinción del gobierno de Rosas con el "caudillismo", es el sanjuanino quien "al contrario de la mayoría de los investigadores, supo dar efectivamente cuenta, tanto en su Civilización y barbarie como en sus demás escritos sobre el tema” (p. 89).

Al mismo tiempo, sostiene Myers, Sarmiento con su Facundo es una referencia ineludible porque “tiende a arrastrar el término de 'caudillo' de su

${ }^{47}$ A esta razón posiblemente respondió la opción de Rojas por reducir el Facundo de Biblioteca Argentina específicamente a Quiroga.

48 Según vimos, Rojas no lee esa fuente directamente, no obstante toma el Facundo de Obras (1896) en representación del libro de 1874. 
acepción original a otra que, sin ser puramente peyorativa, imbuye sin embargo a la figura del caudillo de todas aquellas cualidades poco recomendables" (p. 84). Pero si en esa obra el sanjuanino logra la consagración como pensador político en torno a la problemática, según la óptica de este reconocido historiador, una cuestión paradójica emerge: el "caudillismo" en el Facundo no representa un concepto "denso" ya que "opera simplemente como un tópico más en el interior de aquella constelación vertiginosa de analogías múltiples que se superponen las unas a las otras" (p. 83).

A partir de ese panorama, Myers sugiere que para conseguir configurar la idea de Sarmiento en torno al "caudillo" y el "caudillismo", es necesario buscar en otros textos más allá del Facundo "como su Fraile Aldao, su Vida del Chacho, o su Conflictos y armonías que en su utilización del término aproximan desarrollos posteriores" (Myers, 1998, p. 84). El filoso análisis de Jorge Myers no advierte algo expuesto en la historia de la publicación: el Facundo no fue un escrito "dado" o "definitivo", al contrario, con miras políticas el autor le sumó nuevas biografías de "caudillos".

Partiendo de la historicidad del Facundo se puede argumentar que en 1851 Sarmiento realiza una operación política donde condensa el relato contra el "caudillismo" al aunar Quiroga con Aldao. Y en las últimas dos ediciones, a raíz de la síntesis ente Quiroga, Aldao y el Chacho, el libro definitivamente centró el discurso en la cuestión de los "caudillos" y el "caudillismo". Al detenerme en las fuentes empleadas por Myers comprendo el porqué de su planteo. El historiador utilizó el Facundo de Ediciones Culturales Argentinas (1961), y para Aldao toma Vidas de Fray Félix Aldao y El Chacho de la editorial Argos (1947)..$^{49}$ Su lectura se basó en textos actuales, por eso se entiende que leyó por separado lo que Sarmiento aunó en el siglo xIx.

Para la versión del Facundo de $1993,{ }^{50}$ Carlos Altamirano (2005) preparó una introducción que volvió a publicar en Para un programa de historia intelectual. Principalmente el investigador pretende mostrar la complejidad del escrito en cuanto a las teorías explicativas e ideas que confluyen en el mismo. Respecto a la historicidad, Altamirano (2005) expresa "El propio Sarmiento -que no dejó de volver sobre Facundo, entregándolo a la imprenta con va-

${ }^{49}$ Esta versión integra la colección de la Biblioteca Argos dirigida por Luis Baudizzone, José Luis Romero y Jorge Romero Brest.

${ }^{50}$ Sarmiento (1993). El libro sigue, según expresan los editores, el modelo de Facundo preparado por Palcos (1938). 
riantes de importancia en la segunda edición y la tercera-comentaría al dar indicaciones para una cuarta, que el libro era 'una especie de poema, panfleto e historia"” (p. 38).

Pero en realidad esta alusión al camino recorrido por la obra no busca repensar las ediciones; tiene otro fin, el historiador apunta a discutir con aquellos que intentan encasillar la obra dentro de un género o estilo: "Más que un estilo, lo que Facundo deja ver es una variada gama de recursos de estilo o de formas que le dan su particular andadura. En fin, a medida que la unidad dejó de ser una norma, tanto como un principio por discernir en la obra, la cuestión del acuerdo interno del texto perdió interés como problema por resolver" (Altamirano, 2005, pp. 38-39).

Altamirano no deja de leer el Facundo desde la visión canónica, ${ }^{51}$ a pesar de señalar el carácter multiforme y mencionar las otras biografías de "caudillos", 52 aplica los criterios actuales de no problematizarlas dentro del libro. Incluso, dicho investigador, realiza una breve biografía de Sarmiento citando sus diversas publicaciones, pero sin caracterizar a las nuevas ediciones del Facundo aparecidas en las diferentes etapas de la vida del autor.

La semejanza entre Myers y Altamirano -dos destacados historiadores-, a pesar de trabajar aspectos disímiles del Facundo, es clara: ambos analizan la obra desde versiones actualizadas, y no sólo esto, son libros que siguen el formato canónico. Ambos estudiosos, en consecuencia, denotan la efectividad de la edición de 1938, si antes de Palcos podía leerse el Facundo integrado por tres biografías, luego de su intervención la recepción varía según los estándares editoriales del siglo xx.

\section{CONSIDERACIONES FINALES: SOBRE LA NECESIDAD DE REPENSAR LAS EDICIONES CANÓNICAS}

Para finalizar quiero detenerme en dos consideraciones. Primero, la historia póstuma del Facundo devela que el proceso de apropiación de los editores ini-

${ }^{51}$ Utiliza como fuentes el Facundo de Espasa Calpe (Sarmiento, 1993) y Ediciones Culturales Argentinas (Sarmiento, 1961).

${ }_{52}$ “Sarmiento escribió numerosas biografías, la del fraile Aldao, la del 'Chacho' Peñaloza, la de Franklin, la de San Martín, la de su hijo Dominguito, entre otras” (Altamirano, 2005, p. 25). 
ció inmediatamente producido el deceso de Sarmiento. Facundo comenzó a sufrir el cercenamiento de sus partes ya desde la versión aparecida en Uruguay (1888-1889). También desde temprano se operaron cambios en torno al carácter de la obra, alejándola de su faceta político original para llevarla a una moral. Sin embargo, entre otras cuestiones, lo que quise destacar en el transcurso del artículo es que la intervención de Palcos será la más exitosa debido a que, para la camada de lectores perteneciente a la segunda mitad del siglo xx hasta la actualidad, su Facundo representa la mejor edición. Esto entrama aceptar un libro de tinte literario, donde se margina el relato "caudillista" de Aldao y el Chacho que Sarmiento pensó para complementar a Quiroga.

El otro punto en el que preciso detenerme es la necesidad de volver a las fuentes primarias al momento de realizar trabajos historiográficos. ¿De qué sirve historiar una obra clave de Sarmiento y de la historia argentina como es Facundo? Precisamente, si lo que se pretende estudiar es el pensamiento sarmientino, resulta sustancial recurrir a sus textos evitando los filtros editoriales que aplican modificaciones con criterios ajenos al autor. El peligro del anacronismo es latente cuando no se consultan los documentos primarios, precisamente en este trabajo busqué exponer las posibles faltas en las que los historiadores podemos incurrir al perder de vista la complejidad histórica de un escrito como el Facundo.

\section{LISTA DE REFERENCIAS}

Alberdi, J. (1897). Belgrano y sus historiadores-Facundo y su biógrafo. En Escritos póstumos de J. B. Alberdi (t. v). Buenos Aires: Alberto Mokes.

Altamirano, C. (2005). Introducción al Facundo. En C. Altamirano, Para un programa de historia intelectual (pp. 25-61). Buenos Aires: Siglo XXI.

Ara, G. (1958). Las ediciones del Facundo. Revista Iberoamericana, XXIII(46), 375-394.

Bertoni, L. (2007). Patriotas, cosmopolitas y nacionalistas. La construcción de la nacionalidad argentina a fines del siglo XIX. Buenos Aires: Fondo de Cultura Económica.

Cabo, J. y Nijensohn, C. (2012). Sarmiento a través de sus ediciones. En Noé J. (dir. de obra), A. Amante (dir. de vol.), Historia crítica de la literatura argentina. (Vol. 4: Sarmiento, pp. 725-751. Buenos Aires: Emecé.

Carilla, E. (1959). Dos ediciones de Facundo. Boletín de Literaturas Hispánicas, 1, 45-56. 
Cataruzza, A. (2001). Debates y representaciones de la historia nacional. En A. Cataruzza (dir.), Crisis económica, avance del Estado e incertidumbre política (1930-1943) (pp. 429-476). (Nueva Historia Argentina, t. viI). Buenos Aires: Sudamericana.

Chartier, R. (1993). Libros, lecturas y lectores en la Edad Moderna. Madrid: Alianza.

Degiovanni, F. (2008). Los textos de la patria. Nacionalismo, políticas culturales y canon en Argentina. Rosario: Beatriz Viterbo.

Devoto, F. y Pagano, N. (2010). Historia de la historiografía argentina. Buenos Aires: Sudamericana.

Dottori, N. y Zanetti, S. (1977). Criterio de esta edición. En D. F. Sarmiento, Facundo (pp. LIII-LIv). Caracas: Biblioteca Ayacucho.

Falcón, R. (2000). Militantes, intelectuales e ideas políticas. En R. Falcón (dir.), Democracia, conflicto social y renovación de ideas (1916-1930) (pp. 323-356). (Nueva Historia Argentina, t. vi). Buenos Aires: Sudamericana.

Fernández, H. (2016). Sarmiento y su plan de gobierno para la Argentina: una aproximación a partir del estudio de la concepción del puerto en las ediciones del Facundo. Res Gesta, 52, 123-138. Recuperado de https://erevistas.uca.edu.ar/index. php/RGES/article/view/774

Fernández, H. (2017). El Facundo de Sarmiento: una lectura a la edición de 1851. Temas de historia argentina y americana, 2(25), 29-38. Recuperado de https://erevistas. uca.edu.ar/index.php/THAA/article/view/1021

Garrels, E. (1988). El Facundo como folletín. Revista Iberoamericana, LIV(143), 419-447. Gowa, A. (1948). Exposición de las ediciones de "Facundo". Buenos Aires.

Merbilhaá, M. (2014). 1900-1919. La organización del espacio editorial. En J. de Diego (dir.), Editores y políticas editoriales en Argentina (18810-2010) (pp. 31-61). Buenos Aires: Fondo de Cultura Económica.

Moglia, R. (1955). Fijación del texto, prólogo y apéndices. En D. Sarmiento, Facundo o civilización y barbarie en las pampas argentinas (pp. VII-XIV; 275-294). Buenos Aires: Peuser.

Myers, J. (1998). Las formas complejas del poder. En N. Goldman y R. Salvatore (comps.), Caudillismos rioplatenses. Nuevas miradas a un viejo problema (pp. 83-100). Buenos Aires: Eudeba.

Pagliai, L. (2012). Facundo: la historia del libro. En Noé J. (dir. de obra), A. Amante (dir. de vol.), Historia crítica de la literatura argentina. (Vol. 4: Sarmiento, pp. 33-66). Buenos Aires: Emecé.

Pagliai, L. (2013). Manual de literatura argentina (1830-1930). Bernal: Universidad Nacional de Quilmes.

Palcos, A. (1929). Sarmiento. Buenos Aires: El Ateneo. 
Palcos, A. (1934). El Facundo. Rasgos de Sarmiento. Buenos Aires: El Ateneo.

Palcos, A. (1938). Prólogo y notas. En D. F. Sarmiento, Facundo (pp. xxiII-XxIV). La Plata: Universidad Nacional de La Plata.

Palcos, A. (1940). El dogma socialista. La Plata: Universidad Nacional de La Plata.

Palcos, A. (1945). El Facundo. Rasgos de Sarmiento. Buenos Aires: Elevación.

Palcos, A. (1961). Prólogo y notas. En D. F. Sarmiento, Facundo (pp. IX-XII). Buenos Aires: Ediciones Culturales Argentinas.

Palti, E. (2009). El momento romántico. Nación, historia y lenguajes políticos en la Argentina del siglo XIX. Buenos Aires: Eudeba.

Quattrocchi-Woisson, D. (1995). Los males de la memoria. Historia y política en la Argentina. Buenos Aires: Emecé.

Rojas, R. (1916). Noticia preliminar. En D. Sarmiento, Facundo (pp. 11-25). Buenos Aires: Librería La Facultad.

Rubinich, L. (2003). La modernización cultural y la irrupción de la sociología. En D. James (dir.), Violencia, proscripción y autoritarismo (1955-1976) (pp. 245-279). (Nueva Historia Argentina, t. IX). Buenos Aires: Sudamericana.

Sarmiento, D. (1845). Civilizacion i barbarie. Vida de Juan Facundo Qiroga. I aspecto físico, costumbres, $i$ abitos de la Republica Arjentina. Santiago: Imprenta del Progreso.

Sarmiento, D. (1851). Vida de Facundo Quiroga i aspecto fisico, costumbres i hábitos de la República Arjentina, seguida de Apuntes biográficos sobre el jeneral frai Felix Aldao. Santiago: Imprenta de Julio Belín y Compañía.

Sarmiento, D. (1868). Facundo; ó, civilizacion i barbarie en las pampas arjentinas. Nueva York: D. Appleton y Compañía.

Sarmiento, D. (1874). Facundo ó civilizacion i barbarie en las pampas argentinas. París: Librería Hachette y Cía.

Sarmiento, D. (1888-1889). Facundo o civilizacion i barbarie (t. I, II y III). Montevideo: Tipografía Americana.

Sarmiento, D. (1889a). Obras de D. F. Sarmiento. Tomo vir. Quiroga, Aldao, el Chacho 1845-1863. Santiago de Chile: Imprenta Gutenberg.

Sarmiento, D. (1889b). Civilizacion i barbarie. Vidas de Quiroga, Aldao y el Chacho. Buenos Aires: Lajouane.

Sarmiento, D. (1896). Civilizacion y barbarie. Buenos Aires: Imprenta Mariano Moreno.

Sarmiento, D. (1903). Facundo. Buenos Aires: La Nación.

Sarmiento, D. (1938). Facundo. La Plata: Universidad Nacional de La Plata.

Sarmiento, D. (1961). Facundo. Buenos Aires: Ediciones Culturales Argentinas.

Sarmiento, D. (1977). Facundo. Caracas: Biblioteca Ayacucho. 
Sarmiento, D. F. (1993). Facundo. Buenos Aires: Espasa Calpe.

Scarano, M. (2012). El libro y su autor: las mutaciones textuales del Facundo. Estudios de Teoría Literaria, 1, 53-61. Recuperado de https://fh.mdp.edu.ar/revistas/index. php/etl/article/view/70

Tacca, O. (2000). Los umbrales de Facundo y otros textos sarmientinos. Buenos Aires: Academia de Letras.

Terán, O. (2000). El pensamiento finisecular (1880-1916). En M. Lobato (dir.), El progreso, la modernización y sus límites (1880-1916). (pp. 327-363). (Nueva Historia Argentina, t. v). Buenos Aires: Sudamericana.

Terán, O. (2012). Historia de las ideas en la Argentina. Diez lecciones iniciales, 1810-1980. Buenos Aires: Siglo XXI.

Willson, P. (2004). La Constelación del Sur. Traductores y traducciones en la literatura argentina del silgo xx. Buenos Aires: Siglo XXI. 